\title{
Inclusion Of Student With Special Needs Within Higher Education In UAE: Issues And Challenges
}

Eman Gaad, British University in Dubai, UAE

Mishal Almotairi, The Public Authority for Applied Education \& Training, Kuwait

\begin{abstract}
This is an oral interactive presentation supported by evidences that present the current status of inclusion of students with special needs in the Higher Education sector in the UAE. It looks at the related issues and challenges in a country that is certainly heading towards inclusion of all learners in regular education following the ratification of the UN Conventions on the Rights of Persons with Disabilities. Issues of supporting students in the higher education sector will be discussed as well as what could be done to include such students effectively and to insure students involvement in decision making when providing for their needs in higher education. The presentation ends with recommendations for future practice.
\end{abstract}

Keywords: UAE; Higher Education; Special Needs

\section{INTRODUCTION}

nclusion is a phenomenon and a worldwide movement which is at the top of the global agenda. Inclusion needs attention from the educators as a means of providing an appropriate education for all students. In other words, inclusion can be defined as "serving students with a full range of abilities and disabilities in
the general education classroom, with appropriate in-class support" (Roach, 1995 as cited in Bennett, Bruns \& Deluca, 1997). This means that schools within a catchment area of any child should cater for all students regardless of their abilities or disabilities (Foreman 2008). The philosophy behind inclusion is 'equity in education' which means all children have the right to be educated properly. Many international forums stress on the importance of providing appropriate education for all students regardless of their abilities or disabilities.

The inclusive education for students with special educational needs and disabilities in the UAE was until recently under two ministries, the Ministry of Social Affairs (MOSA) and the Ministry of education (MOE), which to a certain extent, is considered a barrier to the inclusive education process. According to Gaad (2004b), this dual management is not only questioned from a human rights perspective, but also raises questions about its efficiency.

The United Arab Emirates (UAE) adopted this international movement by introducing a federal law in 2006, which was amended in 2009, for the rights of people with special needs. This law came to regulate the rights of persons with disabilities including their education rights. As a result, the Ministry of Education (MoE) introduced a new initiative for including students with special needs in mainstream schools across the UAE. New guidelines were created to regulate the inclusion initiative in the country and schools started to accept different disabilities, which was not the case before this law. Prior to the introduction of this law, schools used to refuse students with certain disabilities, such as Down syndrome and autism, and only accepted less obvious disabilities, such as students with learning disabilities. Research done in the field of special needs in the UAE as whole is very scarce, let alone inclusion as a practice in the country. Some papers were found on investigating the educational offers provided to students with disabilities and even fewer where found on the inclusion of all disabilities. The country itself is young and all its educational initiatives are new, including the new federal law for the rights of persons with disabilities which were only implemented in 2006. School for All was announced in 2009 to mark a new era of moving the 
education responsibilities of all individuals, including those with special needs and disabilities, to the Ministry of Education, while the social responsibilities stayed with Ministry of Social Affairs. However, when it comes to people with disabilities in higher education there are many steps to be taken to ensure that such students are prepared and to also ensure that the higher education sector can support them and meet their full potentials.

This paper examines the current status of students with special needs in the Higher Education sector in the UAE. It looks at the related issues and challenges in a country that is certainly heading towards inclusion of all learners in regular education systems following the ratification of the UN conventions on the Rights of Persons with Disabilities. Issues of supporting students in the higher education sector will be discussed in light of the current provisions and legislations. Activities of leadership of higher education institutes will also be discussed as well as what could be done to include such students effectively and to ensure student involvement in decision making when providing for their needs in higher education. The paper ends with recommendations for future practice.

\section{METHODOLOGY, ETHICS \& LIMITATION}

In order to examine the current status of inclusion of students with special needs in the Higher Education sector in the UAE, a set of methods were carefully selected to match this kind of research. This research paper is based on a qualitative methodology approach which helps in showing the finer details of an issue and is more descriptive in its nature (Mertens 1998). According to Denzin \& Lincolne (2001 as cited in Mertens and Mclaughlin 2004: p. 35), a qualitative approach is "designed to provide a rich, contextualized picture of an educational or social phenomenon" and since inclusion is a trend and a phenomena, this particular approach was chosen to carry out this study. Additionally, qualitative approaches allow for in-depth exploration of the topic of the study in order to improve it (Devatak, Clazar \& Vogrine 2010).

Having decided on using the qualitative approach for this particular study, a triangulation of data collection methods were used to ensure the validity of its results, including interviews, observations and document reviews, in addition to literature research related to the topic. According to Cohen etal (2000:112) triangulation means "the use of two or more methods of data collection in the study of some aspect of human behavior". The triangulation was composed of three semi-structured interviews and one observation of a lecture, along with reviewing of official documents from the Centre of Disability services which are circulated in one of the largest federal universities in the UAE. Documents used in this study were mostly in Arabic, which is the universities' and the Ministry of Higher Education and Research's (MoHER) primary language relied on in all communication mediums. Nevertheless, due to the vast number of collected documents that were reviewed in Arabic, only relevant parts were translated into English and used in this study. The other method used in collecting data in this study was observation. Observation sought to be "the appropriate technique to get at real life in the real world" (Robson 202, p. 310) which means observing a situation while it is happening in order to analyze it. The last method used in collecting data was semistructured interviews, which allowed for the adjustment of questions depending on the situation's direction at the time of the interview. According to Cohen et al (2000) semi-structure questionnaires in an interview are used to control the reliability. Moreover, interviews are seen as time-consuming, and so interviews were conducted either face-to face or over the telephone to save time. Data obtained from the interview was recorded and responses were read to the interviewee to check their answers. Also, since interviewees discussed various matters and tended to go off topic, summarized accounts of the interviews were conducted in order to highlight the main points discussed with interviewees. Interviews were carried out after attending the lesson observations to eliminate any influence of the interviews on the observation.

\section{FINDINGS}

The followings are the main related issues that were found urgently pressing with regards to the provision of educational services for students with disabilities in the higher education sector in the UAE.

\section{Training for Staff and Learning of Students with Special Needs in Higher Education}

The educational system has been applying the cognitive development theories of Piaget and Vygotsky for many years. The way children learn and mentally grow plays a central role in their learning processes and abilities. 
By understanding the progression of cognitive development, teachers enable themselves to better cater to the unique needs of each child.

By using hints and pointers from teachers, parents, and peers who have already grasped the desired concept, children are able to form their own path towards a solution and by doing this eventually to self-regulate, or think and solve problems without the help of others (Slavin, 2003, p. 44). Piaget believed that intelligent and that learning takes places after development.

Alternatively, Vygotsky felt that learning can occur before development and that children learn because of history and symbolism (Slavin, p. 30, 43). Vygotsky (1978) also believed that children value input from their surroundings and from others.

There is no specific way to teach students with special needs; instead, varying the methodologies of learning can have a better outcome for students with SEN. As a result, for inclusion to take effect, governmental schools must be prepared in all aspects. Moreover, secondary schools must have a framework of how students with SEN can transfer into postsecondary education with a prepared background and clear provision. In addition, most of the learners with SEN who enter postsecondary education need remedial courses. Even when they receive remediation, these students are less likely to earn a degree or certificate than students who do not need remediation (Wirt et al., 2004).

According to the research undertaken, interviewees, who were mostly made up of lectures and instructors, revealed that they had no professional training in how to deal with and teach such learners. They also stated that teaching strategies were specified and 'trial and error' was the key to success in the case of successful stories; they kind of 'played it by ear' in order to survive in the lecture hall with such students.

Some interviewees actually stated that they relied so much on students themselves to 'teach' them how to teach'. As a researcher I felt that with most participants they survived the whole experience by engaging students to a great extent in the planning and delivery of the process. That approach was based on the theory that 'students have such needs and disabilities all their lives and we (referring to teachers) should trust them with the best way to go about the teaching processes.

Data from interviews showed suggestions from faculty for future practice:

1. Training from Smart Board consultant on how to use the Smart software to prepare educational lessons

2. Disability center needs to have a good communication system for distributing resources

3. Improve function of Smart Board-operation

4. Training on Blackboard class organizational system

5. $\quad$ Equipment needs to be available from Disability Center

6. Professional development in specific disabilities, learning needs, and accommodations

7. Communication to faculty about needs of students who signed up for classes

8. Center needs to provide assessment and recommended accommodations and sends to advisors and seek feedback from the advisors from the students themselves once such accommodations are implemented

9. $\quad$ Self-determination courses the students to become advocates

10. Extra time to prepare, credit hours for extra courses

11. University Policy on accommodating for participation in courses

12. Safety and health policy needs to be clarifies to staff especially in the case of emergency and evacuation

13. Orientation for all staff about emergency procedures

\section{Accommodations for Disability}

Students with learning difficulties may face numerous challenges once moved from high school to postsecondary level. First, learning disabilities are hidden disabilities, because they are not physically evident or noticeable when in general contact with the others (Field, 1996: Getezel \& Gugerty, 1996, as cited in Janiga, S. et al. 2002). Thus, the needs of students with LD are not as readily understood and accepted as the needs of students with more obvious disabilities (e.g., visual, hearing or orthopedic impairments). 
The differences between secondary and postsecondary education also create problems for students with LD. Typically, a university setting provides less student-teacher contact and larger class sizes (Lerner, 1997 as cited in Janiga, S. et al. 2002). College courses usually require long range projects and infrequent evaluations, in contrast to short-term assignments and frequent grading experienced in high school.

College students have more unstructured time to manage and often lose their familiar support network of family and friends. Although all students in college experience these new learning conditions, students with LD are at greater risk of failure (Lerner, 1997). Their ability to self-assess strengths, deficits, interests, and values is often impaired, and they may find decision making a difficult and problematic process (Cummings et al., 2000; Levinson \& Ohler, 1998 as cited in Janiga, S. et al. 2002).

Thus, students with LD need assistance to determine the specific accommodation they need and to make career decisions. Also, they must acquire self-advocacy skills; they must learn how to communicate their own strengths and weaknesses to professors in order to receive appropriate accommodations (Cummmings et al., 2000, as cited in Janiga, S. et al. 2002). However, the identification of students who need these services is often difficult (Gajar, 1992, as cited in Janiga, S. et al. 2002).

The majority of the referrals received by postsecondary programs that serve students with disabilities are from parents or self-referrals prior to admission, but for a large proportion of students, learning difficulties are only reported after they have commenced with the college curriculum (Gajar, 1992).

The responsibilities of the students also rely on how to identify appropriate supports, select their courses, and monitor their utility of requested accommodations. Schools should help students realize that they must be qualified for admission into a postsecondary institution and must remain eligible by maintaining satisfactory performance, both academically and socially. Therefore, it is critically important that students understand the specific nature of their disabilities and related legal rights and responsibilities (Shaw, Madaus \& Banerjee, 2009).

\section{Advocacy and Cultural Issues}

A pressing question that was explored by participants was: Are there any differences between attitudes of school teachers and university lecturers when it comes to teaching students with special needs and/or disabilities? Here is a brief discussion of school teachers' attitudes in the UAE supported by literature. There are no doubts that the attitude of teachers is a very important variable in the success of including students with exceptional learning needs in regular classrooms (Stewart, 1990, as cited in Gaad, 2004). In a study that was set to examine General Education teachers' attitudes towards including students with disabilities in regular classrooms in the UAE, Alghazo and Gaad (2004) found that teachers in the UAE tended to have negative attitudes towards the inclusion of students with disabilities in the regular education classrooms. Results also indicated that male teachers had more negative attitudes. The study showed that the years of teaching experience was influential in determining teachers' acceptance of inclusion. As teachers gained more experience, they seem to be more accepting of the inclusion of students with disabilities in their classrooms (Alghazo and Gaad 2004).

Lecturers and instructors of the interviewee sample from the higher education sector showed no difference from the above. Words like 'those difficult cases' and 'the demanding different students in my lecture' were mentioned. The attitude in general was rather looking at their disabilities not their abilities.

\section{RECOMMENDATION}

Based on the findings of the study, few recommendations are proposed regarding the practice of inclusion in the Higher Education sector in the UAE. Most important is the training issue or lecturers working with students with special needs. Lecturers need to be trained on differentiation and modification in order to allow the included students to access the curriculum and to improve their learning outcomes. They need to adopt the philosophy behind inclusion and not see it as a compulsory job. Better implementations of the individualized Educational Plan (IEP) should be encouraged to report and monitor the progression of the included student. In addition, universities and further education institutions should be allocated proper funding to support inclusion and provide the students and 
lecturers with what they may need to make inclusion a success. Moreover, the availability of personnel is needed to enhance the practice of inclusion. Such personnel may include speech therapists, psychologists, teachers' aid and resource room teachers. In addition, the country lacks accurate statistics of special needs. Knowing the number of children with special needs will help in designing proper programs for them in the long run thus better preparing the higher education sector. In addition, it will allow for better funding based on their needs. Lastly, an urgent need is for an entity to supervise the provision of special needs for all the country.

\section{CONCLUSION}

The history of special education is summarized by Casey (1994 as cited in Brusling \& Pepin, 2003) as moving from neglect in the $20^{\text {th }}$ century to segregation until the $1960 \mathrm{~s}$, to the inclusion in the present. Inclusion is a journey; it is not a destiny (Mittler, 2000). Villa \& Thousand (2005:78) claimed that "transition to inclusive schooling no longer seems impossible", however it cannot happen within a year in a country where segregation in education has dominated for a long time. The UAE as a young country including its education system has embraced inclusion of students with special needs in mainstream schools and supported that with a policy in the form of the federal law 29/2006 for the rights of persons with special needs. In spite of inclusion being recently adopted in the country, notably, a tremendous improvement has occurred on the provision of special needs. Inclusion is a step forward from segregating students with special needs to private the need of older students must be taken into consideration before planning and implementing inclusive education.

In conclusion, the data collected through the different means of data collection for this study (interview, observation and documents review) showed that there is an acceptance in general for including students with special needs in the higher education sector in across UAE due to the positive influence of the personnel management system at such sector. Yet, that was an obvious fear of how to deal with those students. A policy found to be supportive to the practice of inclusion; however, it was not recognized at the university level. The effectiveness of the federal law 29/006 and the amended version of 2009 are limited as still may teachers/lecturers do not know about it. It seemed to be well known at the policy makers' level and is not known to the teachers/lecturers. Inclusion was found to be a practice in the higher education sector that faced barriers. Attitudes towards inclusion are still affected by the disability type and cultural issues.

Such attitudes should be changed through awareness campaigns within all society sects. Family roles seemed to improve and change from non-participatory to partnering with the higher education sector. Yet, the provision of special needs improvement in order to serve those students with special needs and/or disabilities and cater to their needs, allowing them to reach their potentials improves their learning outcomes. Professional development found to be an important element in the success of inclusion. Training and providing specialized therapists needs much attention from the decision makers in order to make inclusion work in the higher education sector. A set of recommendations has been given in the study to improve the provision of special needs. Such recommendations are related to better implementations of policies of special needs represented in the federal law. Additionally, lecturers' and teachers' training is in much need for more concentration. Universities in the country need specialized experts and therapists to serve the included students. IEPs need to be implemented and monitored in higher education entities and at the MoHER level. Differentiation is another field which need is required to make inclusion work. Modification and adaptation is called for depending on the special needs the student have.

\section{AUTHOR INFORMATION}

Professor Gaad is the Dean of the Faculty of Education and a Full Professor of Special and Inclusive Education at British University in Dubai. Professor Gaad is an Honorary Fellow at the internationally reputed University of Birmingham, UK. She led the university's special and inclusive Master's program for many years and currently leads the Doctorate program. She founded and heads the educational committee in one of the largest NGOs in the UAE, UAEDSA (United Arab Emirates Down Syndrome Association). Professor Gaad is one of the governors of Dubai College and on the Board of Directors of several non-profit organizations in the UAE. She has advised policy and decision makers as a senior consultant for both governments of Dubai and Abu Dhabi on disability related issues. She is also a winner of HH Princess Haya Award for Special Education as best distinguished individual research in 2012, and in the same year was awarded the Global Leadership in Education Award from the Asian 
Leadership Award Board. Professor Gaad is also on the international advisory board for international peer-reviewed journals and an associate editor for others. She was seconded for two years as the first Director of Disability Services in Dubai Government's Community Development Authority. A committed advocate for the educational and social rights for people with disability, she is a UNESCO Consultant on inclusion of learners with disabilities in regular schools. Professor Gaad has published the findings of her research work in international journals and her single authored book 'Inclusive Education in the Middle East' by Routledge in 2010 is very popular among scholars and researchers internationally. She works with local communities to help parents of children with special needs to facilitate their placement in regular schools. Professor Gaad is currently, and has been for 6 years, a National Representative of the World Forum on Early Care and Education. She has established her herself as a world class researcher, advocate, certified assessor, and a professional social trainer who is particularly interested in training families and workers in the field of social development. Over the last 15 years she has become a frequent media figure on hundreds of live on-air radio and TV programs, as well as hundreds of articles published in local and regional newspapers. Professor Gaad is a sound academic, an External PhD Examiner for reputed UK universities, and is a recognized international scholar in the field of special and Inclusive Education. E-mail: eman.gaad@buid.ac.ae (Corresponding author)

Mishal Almotairi is a lecturer at The Public Authority for Applied Education \& Training in Kuwait. He is an advisor to the Minister of Information and Youth Affairs and is a member of his Higher Advisory Committee. E-mail: m.aljnoobi@googlemail.com

\section{REFERENCES}

1. Bennett, T., Bruns, D. \& Deluca, D. (1997). Putting inclusion into practice: Perspectives of Teachers and Parents. Exceptional Children Journal, 64(1).

2. Cohen, L., Manion, L. and Morrison, K. (2000) Research methods in Education. $5^{\text {th }}$ ed. London: Routledge.

3. $\quad$ Falmer Foreman. (Ed.) (2008). Inclusion in action ( $2^{\text {nd }}$ ed.). Sydney: Cengage.

4. Gaad, E., (2004b). Pre-services attitudes towards a career in special education in the United Arab Emirates. College Student Journal, 38(4), pp. 619-632.

5. Gaad, E. (2010). Inclusive Education in the Middle East. New York: Routledge.

6. Mertens, D.M and McLaughlin, J.A. (2004). Research and Evaluation Methods in Special Education. California: Crown Prince.

7. Ministry of Education, (2010). General rules for the provision of special education programs \& services: public \& private schools. UAE: Ministry of Education Publication, $1^{\text {st }}$ edition.

8. Ministry of Social Affairs, (2006), UAE Federal Law No 29 of the Year 2006 on the Rights of People with Special Needs. UAE: Ministry of Social Affairs Publication.

9. Mittler, P. (2000) Working Towards Inclusive Education: Social Contexts. London: David Fulton Publishers.

10. Villa, R. A and Thousand, J. S. (ed) (2005) Creating an Inclusive School. (2 ${ }^{\text {nd }}$ Ed). Alexandria, Virginia, US: ASCD publications. 